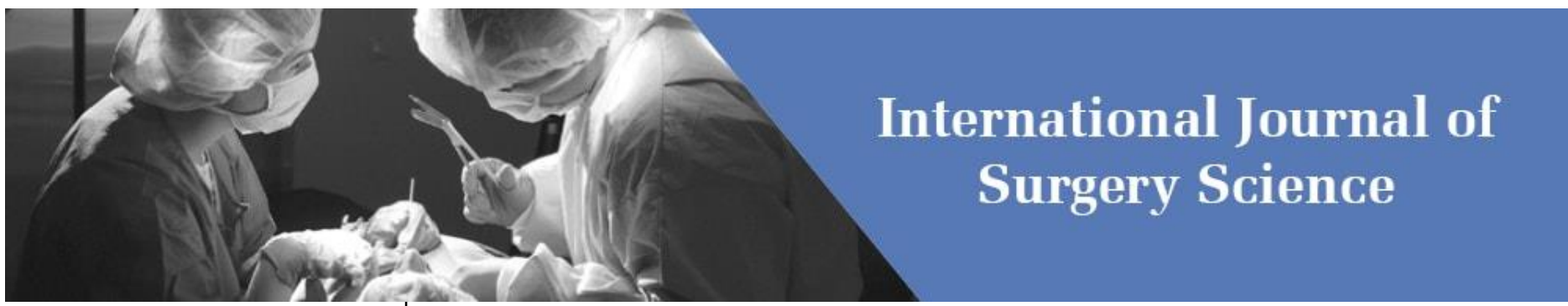

E-ISSN: 2616-3470

P-ISSN: 2616-3462

(C) Surgery Science

www.surgeryscience.com

2020; 4(3): 82-84

Received: 08-05-2020

Accepted: 10-06-2020

Dr. Ajay A Gujar

(a) General Surgery Department-

Amruta Surgical and Maternity

Home Ghatkopar West Mumbai,

Maharashtra, India

(b) Ex Associate Professor LTMMC

and LTMGH Sion Hospital

Mumbai, Maharashtra, India

(c) HOD, Professor, Consulting

General and Laparoscopic Surgeon,

Dr. D. Y. Patil Hospital and

Medical College Nerul, Kohinoor

Hospital Vidyavihar Mumbai,

Maharashtra, India

Dr. Attman P Velani

Dr. D. Y. Patil Hospital and

Medical College Nerul, Navi

Mumbai, Maharashtra, India

Dr. Amrita A Gujar

K.J. Somaiya Hospital and

Research Centre Sion Mumbai,

Maharashtra, India

Dr. Aashay Dharia

K.J. Somaiya Hospital and

Research Centre Sion Mumbai,

Maharashtra, India
Corresponding Author:

Dr. Attman P Velani

Dr. D. Y. Patil Hospital and

Medical College Nerul, Navi

Mumbai, Maharashtra, India

\section{Is the Anterior component separation technique sufficient for ventral hernia?}

\author{
Dr. Ajay A Gujar, Dr. Attman P Velani, Dr. Amrita A Gujar and Dr. \\ Aashay Dharia
}

DOI: https://doi.org/10.33545/surgery.2020.v4.i3b.473

\section{Abstract}

Background: Large ventral hernia continued to possess a great challenge to general surgeon. Historically a variety of permutation and combination of repair have evolved. However, no single surgical repair can meet the requirement completely. A combination of component separation accompanied with mesh repair needs to be studied and analyse.

Aim: To study percentage of patients required only anterior or both (anterior and posterior) component separation.

Methods: 30 Patient undergoing component separation were evaluated. Tissue repair comprises of component separation with creation of flap from rectus sheath in order to breach midline and creation of new midline. This followed by preperitoneal (retro rectus) or above the rectus muscle polypropylene soft mesh enforcement with complete cover over mesh by anterior rectus sheath. So, in our patients mesh never fixed above the rectus sheath.

Results: In our study we realised that most of the large defect hernias are required more anterior compartment separation. Both compartments separation is required only in complex, and more than $10 \mathrm{~cm}$ defect of anterior abdominal wall hernia.

Conclusion: Anterior component separation is often required and enough for abdominal wall reconstruction with good cosmetic contour without any recurrence than both component separation.

Keywords: anterior component separation (ACS), posterior component separation (PCS), ventral hernia

\section{Introduction}

The component separation technique (CST) was introduced for abdominal wall reconstruction to treat large, complex hernias ${ }^{[1]}$. The options for closing large and complex abdominal wall defects, including primary repair, mesh, and distant muscle flaps, have yielded suboptimal results ${ }^{[1]}$. Albanese and Ramirez first developed the CST to address this issue ${ }^{[2-6]}$. "CST is based on the concept of re-establishing a functional abdominal wall with autologous tissue repair" [1]. "The procedure involves dividing the relatively fixed external oblique aponeurosis and muscle, elevating the rectus abdominis muscle from its posterior rectus sheath, and then mobilizing the myofascial flap consisting of the rectus, internal oblique, and transversus abdominis medially" [1].

In the meantime, numerous different CSTs have been described. In the "classic" CST a distinction is made between the open anterior and posterior approach. In recent years a special type of posterior CST, transversus abdominis release (TAR), was introduced. Furthermore, endoscopic variants of the anterior and posterior CST have been developed. The most recent innovations are the laparoscopic and robot-assisted TAR.

By now, there are several studies and reviews that report on the CST range of topics. But comparisons and assessments of studies are impossible due to technics and placement of mesh. On the contrary, wound infection rates of up to $57 \%$ have been identified ${ }^{[1]}$. 


\section{Material and Method}

From 35 to 75 years both genders selected for this study in last 6 years from January 2015 to January 2020.

Table 1: Gender and age of patients

\begin{tabular}{|c|c|c|}
\hline Gender and age & female & male \\
\hline 35 to 40 yrs. & 3 & 0 \\
\hline 41 to 50 yrs. & 5 & 0 \\
\hline 51 to 60 yrs. & 7 & 2 \\
\hline 61 to 70 yrs. & 7 & 2 \\
\hline 71 to 75 yrs. & 3 & 1 \\
\hline Total & 25 & 5 \\
\hline
\end{tabular}

Table 1 shows female patients were $25(83 \%)$ due to poor abdominal muscle tone, multiple pregnancies, obesity and male were $5(17 \%)$. Total $9(30 \%)$ patients had postop wound infections due to abdominal surgeries.

Table 2: Type of incisions

\begin{tabular}{|c|c|c|}
\hline Type of incisions & Female & Male \\
\hline After Midline incisions & 15 & 3 \\
\hline After paramedian & 3 & 0 \\
\hline After Pfannenstiel & 3 & 1 \\
\hline Recurrent incisional hernia & 4 & 0 \\
\hline Ventral hernia without incision & 1 & 1 \\
\hline Total & 25 & 5 \\
\hline
\end{tabular}
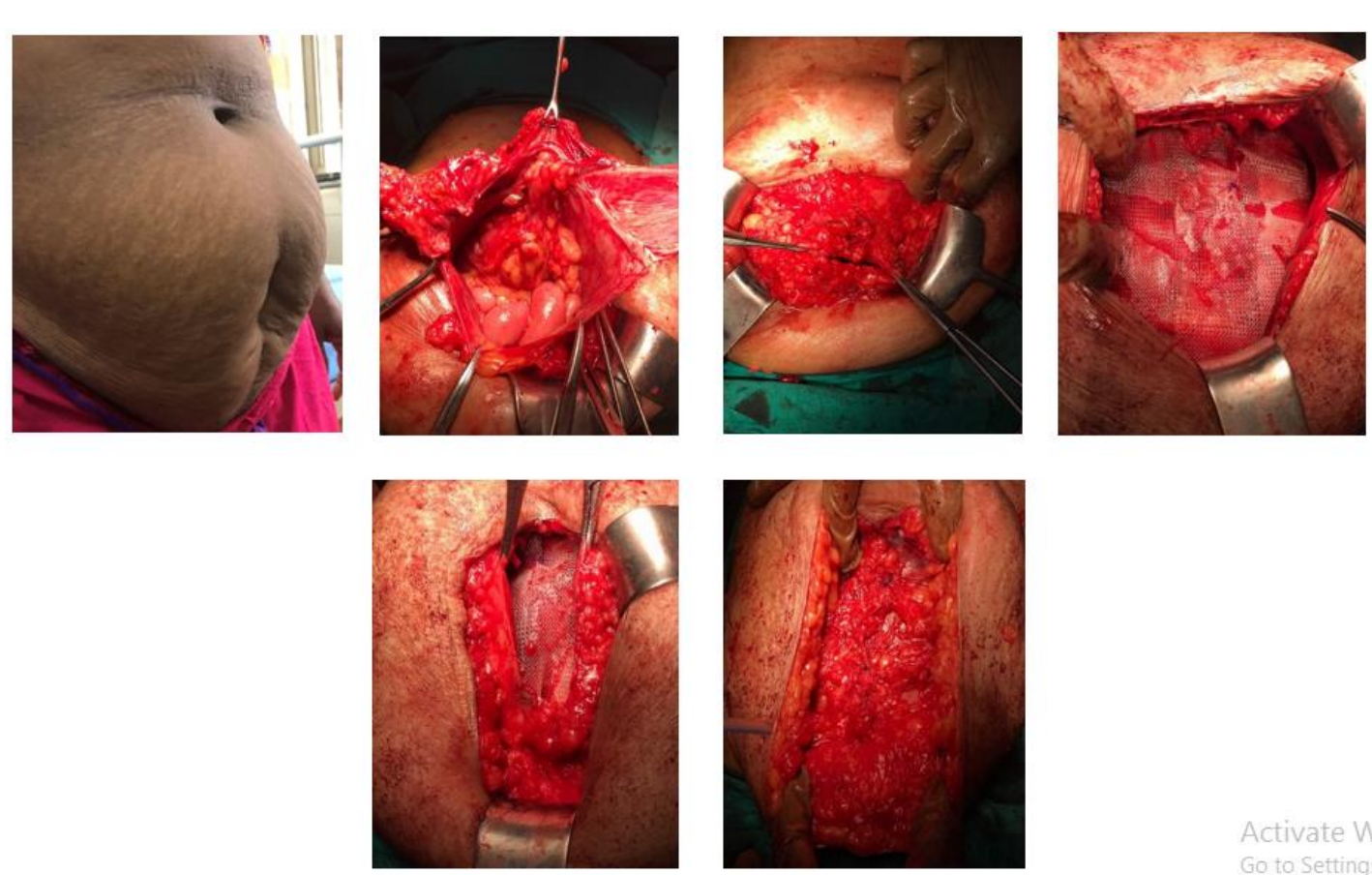

\section{Surgical technique}

\section{Anterior component separation}

We did classical Ramirez technique ${ }^{[8]}$ in 25 cases. The skin flaps were raised by about $5 \mathrm{~cm}$ beyond the midline, the lateralto-lateral border of the rectus muscle (linea semilunaris).

The external oblique was divided into $2 \mathrm{~cm}$ lateral to linea semilunaris, vertically on both the side and separated from the internal oblique. This allows medialization of the rectus. The extent of division of the external oblique depends on the size of the defect. The separation was done till midline could be closed with only normal physiological tension. In some cases, full length division of external oblique aponeurosis was done.

A light polypropylene mesh was put as a preperitoneal (below the rectus muscle) in the six cases and below the anterior rectus sheath in the subsequent nineteen cases. Sixteen-French suction drains were put in the subcutaneous plane, and the skin was closed. However, we encountered skin necrosis in some of these patients (Table 1). Skin necrosis is attributed to division of periumbilical perforators which get divided when skin flaps are raised.

Activate W

Goto Setting

Fig 1: Showing clinical picture and operative steps of ventral hernia repair. Mesh placement done below rectus muscles and anterior rectus sheath completely covered over the mesh.

\section{Posterior component separation}

We have also done posterior component separation ${ }^{[4]}$ in three cases. After initial adhesiolysis, a plane is opened between the rectus muscle and posterior rectus sheath. The posterior rectus sheath was divided $5 \mathrm{~mm}$ medial to linea semilunaris. A plane between the transverse abdominis and internal oblique was created along the length of incision on both sides which allows medialization of rectus. A soft mesh was then inserted as a preperitoneal, and the midline was closed. We could manage to close the midline using this method.

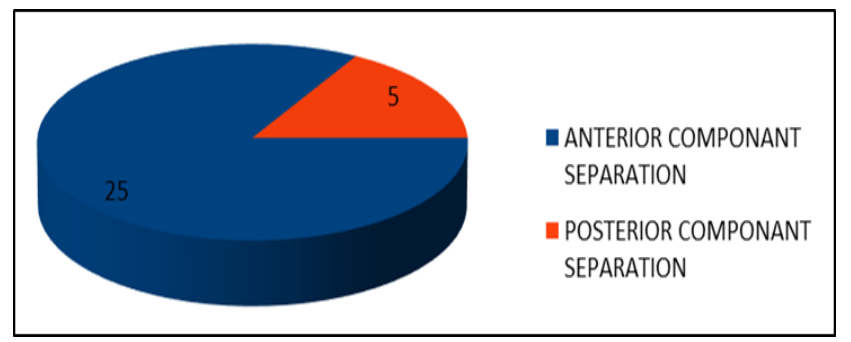

Fig 2: Graph of anterior and posterior component separation 


\section{Results}

Table 3: Showing summary of results in 30 patients

\begin{tabular}{|c|c|c|c|c|}
\hline ACS & $\begin{array}{c}\text { ACS and } \\
\text { PCS }\end{array}$ & $\begin{array}{c}\text { Complete wound } \\
\text { healing in days }\end{array}$ & complication & $\begin{array}{c}\text { Recurrence in } \\
\text { 1to 6 yrs. FU }\end{array}$ \\
\hline 25 cases & 5 cases & $\begin{array}{c}10 \text { to } 14 \text { days }-25 \\
14 \text { to } 24 \text { days- } 04 \\
>24 \text { days- } 01\end{array}$ & $\begin{array}{c}\text { Skin necrosis } \\
\text { Mild } 4 \\
\text { Severe } 1 \text { (sec. } \\
\text { skin suturing) }\end{array}$ & 0 \\
\hline
\end{tabular}

In this study we did anterior component separation in $25(83 \%)$ patients. Only 5 (17\%) patients were required posterior component separation.

All the 30 patients tolerated the procedure very well. Twentyfive cases recovered without complications and discharged within 1 week of time. We encountered necrosis of the skin in five cases, all after anterior CST. Four cases had very minimal necrosis in the peri-umbilical area, which healed with dressings. One had a large area of necrosis which needed to be debrided. Secondary skin suturing done after 2 weeks. (Table 3 ).

\section{Discussion}

Ventral hernia is a common problem. It can be primary or secondary to previous abdominal surgery. The attributing factors for ventral hernia are obesity, multiple pregnancies, smoking, chronic obstructive pulmonary disease, etc. Incisional hernia, in addition, can result from faulty surgical techniques and wound infection. About $10 \%$ of ventral hernias undergo incarceration and need emergency surgery.

If untreated, the natural history of ventral hernias is gradual enlargement. The linea alba serves as the midline anchor for the aponeurotic insertions of the rectus sheath and oblique musculature. Disruption results in gradual enlargement of the hernia defect because of unopposed lateral contraction of the oblique musculature. This leads to widening of hernial defect and large ventral hernia.

Repair of large ventral hernia is a challenge for even experienced surgeons, as there are large defects which are difficult to close. In the earlier time, these large defects were closed using procedures like myofascial flaps or free flaps with high recurrences and complications ${ }^{[7]}$. Off late, these defects are bridged with artificial prosthesis (laparoscopic or open), but leaving the defects open.

However, non-closure of the midline had adverse effects on abdominal wall functions. It does not maintain abdominal contour too.

The major functions of the abdominal wall include: Providing a durable and flexible covering to prevent the abdominal viscera from leaving the abdominal cavity. Protecting internal abdominal organs from trauma/injury. Maintaining the anatomical position of the abdominal organs. Assisting expiration by pushing the abdominal organs towards the diaphragm. Assisting in coughing and vomiting by increasing intra-abdominal pressure.

Component separation technique (CST) is a novel answer to closure of midline with live, active tissues with or without the use of additional prosthesis. Additional prosthesis is must in most of the cases as muscle tone is already poor. This technique was originally described in 1990 by Ramirez ${ }^{[8]}$. Lower hernia recurrence rates, restoration of dynamic abdominal wall function and improvement in back and postural abnormalities have been cited in the Western literature ${ }^{[9]}$. Major issue with this technique is wound-related complications owing to wide undermining of skin flaps. Modification by preserving peri-umbilical perforators can reduce wound-related morbidity as shown in some of recent works ${ }^{[9]}$.

\section{Conclusion}

In our research it is to be concluded that most of the incisional hernias are get repaired with anterior component separation only. The contour of the abdomen gets well maintained and there are no recurrences in this repair. Very rarely posterior component separation needed where anterior rectus sheath does not cover the midline and the areas where abdominal compartment syndrome chances are high.

\section{References}

1. Switzer NJ, Dykstra MA, Gill RS, Lim S, Lester E, de Gara $\mathrm{C}$ et al. Endoscopic versus open component separation: systematic review and meta-analysis. Surg Endosc. 2015; 29(4):787-95. 10.1007/s00464-014-3741-1 [PubMed] [CrossRef] [Google Scholar]

2. Albanese AR. [Gigantic median xipho-umbilical eventration; method for treatment]. Rev Asoc Med Argent. 1951; 65(709-710):376-8. [PubMed] [Google Scholar]

3. Albanese AR. [Liberating incisions in the treatment of large supraumbilical eventrations]. Prensa Med Argent. 1966; 53(38):2222-7. [PubMed] [Google Scholar]

4. Ramirez OM, Ruas E, Dellon AL. Components separation method for closure of abdominal-wall defects: an anatomic and clinical study. Plast Reconstr Surg. 1990; 86(3):519-26. [PubMed] [Google Scholar]

5. Ramirez OM. Abdominoplasty and abdominal wall rehabilitation: a comprehensive approach plastic and reconstructive. Surgery. 2000; 105:425-35. [PubMed] [Google Scholar]

6. Heller L, Mcnichols CH, Ramirez OM. Component separations. Semin Plast Surg. 2012; 26(1):25-8. 10.1055/s0032-1302462 [PMC free article] [PubMed] [CrossRef] [Google Scholar]

7. Dan H, Shell IV, de la Torre J, Andrades P, Vasconez LO. Open repair of ventral incisional hernias. Surg Clin N Am. 2008; 88:61-83. DOI: 10.1016/j.suc.2007.10.008. [PubMed] [CrossRef] [Google Scholar]

8. Ramirez OM, Ruas E, Dellon AL. Components separation method for closure of abdominal-wall defects: an anatomic and clinical study. Plast Reconstr Surg. 1990; 86:519. DOI: 10.1097/00006534-199009000-00023.

[CrossRef] [Google Scholar]

9. Nguyen V, Shestak KC. Separation of anatomic components method of abdominal wall reconstruction: clinical outcome analysis and an update of surgical modifications using the technique. Clin Plastic Surg. 2006; 33:255. DOI:10.1016/j.cps.2005.12.010. [PubMed] [CrossRef] [Google Scholar] 